\title{
Computers can compute better than humans
}

\author{
Waël C. Hanna, MDCM, MBA, FRCSC
}

\author{
From the Division of Thoracic Surgery, McMaster University, Hamilton, Ontario, Canada. \\ Disclosures: Author has nothing to disclose with regard to commercial support. \\ Received for publication July 22, 2018; accepted for publication July 22, 2018; available ahead of print Aug 29, \\ 2018. \\ Address for reprints: Waël C. Hanna, MDCM, MBA, FRCSC, St Joseph's Healthcare Hamilton, 50 Charlton Ave \\ E, Juravinski Tower, Suite T2105 F, Hamilton, Ontario L8N4A6, Canada (E-mail: hannaw@mcmaster.ca). \\ J Thorac Cardiovasc Surg 2018;156:2309 \\ $0022-5223 / \$ 36.00$ \\ Copyright (C) 2018 Published by Elsevier Inc. on behalf of The American Association for Thoracic Surgery \\ https://doi.org/10.1016/j.jtcvs.2018.07.069
}

Lung preservation is a timely and important topic in modern thoracic surgery. The advent of computed tomography screening for lung cancer and our increasing knowledge of the long-term behavior of ground-glass opacities have altered our understanding and management of early stage lung cancer. We are also becoming more aggressive in surgical resection for lung metastases in highly selected patients. As a result, our approaches to lung cancer surgery now rely more heavily on sublobar resections, keeping in mind that the same patients will need to undergo multiple operations (for multiple metachronous tumors) throughout their lifetimes. The natural consequence of this newfound emphasis on lung preservation is that thoracic surgeons will need more accurate models to predict lung function postoperatively.

In this issue of the Journal, Fernández-Rodríguez and colleagues ${ }^{1}$ demonstrate a novel method of predicting postoperative lung function with volumetric computed tomography. They demonstrate that their method, which relies on 3-dimensional computed tomographic modeling, correlates better with true postoperative pulmonary function than the traditional methods of counting the anatomic segments and perfusion scintigraphy. Although the equations they used to compute postoperative pulmonary function are too complex to be applied successfully in daily practice, it is only a matter of time until new computed tomographic software makes volumetric analysis a standard part of any imaging report.

Unfortunately, this work is limited by serious selection bias. Fernández-Rodríguez and colleagues ${ }^{1}$ tested their novel approach on patients who had already been deemed to be surgical candidates by the traditional methods of scintigraphy or segment counting. As such, they were merely able to show that volumetric analysis is better able to describe a known outcome. Patients who were not deemed candidates for operation by standard methods were not included in this analysis. One does wonder, however, whether these patients would be the ideal population to benefit from this technology. What if a patient whose disease was "inoperable" by current standards had it labeled

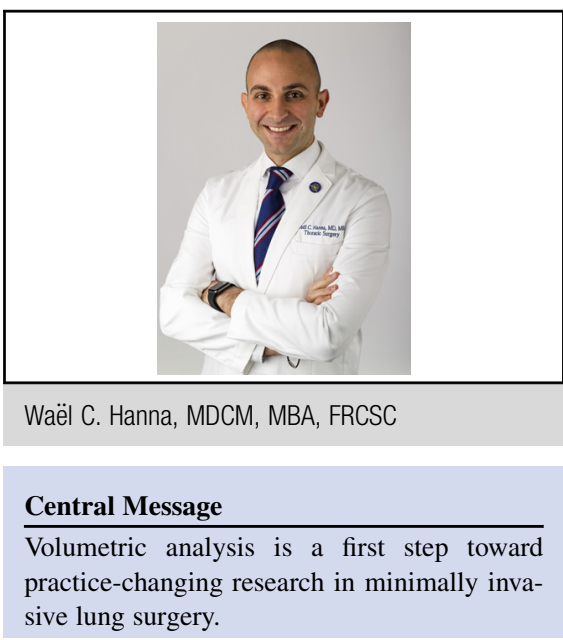

See Article page 2297.

"operable" when volumetric analysis was used to compute the postoperative function? What about a patient who has previously undergone lobectomy for a cancer and another segmental resection for a ground-glass opacity presents with a new lesion that requires resection; could this patient benefit from volumetric analysis to determine operability? The answer remains unknown, because patients who underwent previous thoracic surgery were excluded from this analysis.

Fernández-Rodríguez and colleagues ${ }^{1}$ have demonstrated what we all suspected was true: computers can compute postoperative lung volumes better than humans. This is a crucial step in our continued effort to offer surgery to patients who currently have their lesion labeled "inoperable." It has already been demonstrated that patients with forced expiratory volume in 1 second and diffusing capacity of lung for carbon monoxide less than $50 \%$ predicted can safely undergo thoracoscopic surgery. ${ }^{2}$ Determining whether we can push the envelope further will require some precise volumetric analyses and prediction models-and this article by Fernández-Rodríguez and colleagues ${ }^{1}$ provides the preliminary data for practicechanging research.

\section{References}

1. Fernández-Rodríguez L, Torres I, Romera D, Galera R, Casitas R, MartínezCerón E, et al. Prediction of postoperative lung function after major lung resection for lung cancer using volumetric computed tomography. J Thorac Cardiovasc Surg. 2018;156:2297-308.e5.

2. Donahoe LL, de Valence M, Atenafu EG, Hanna WC, Waddell TK, Pierre AF, et al. High Risk for thoracotomy but not thoracoscopic lobectomy. Ann Thorac Surg. 2017;103:1730-5. 